\title{
Cost Savings as a Result of Bortezomib Vial Sharing in Albania
}

\author{
Florjana Rustemi, PhD Student \\ Albanian University, Albania \\ Ledjan Malaj, Prof. \\ Ela Hoti, Assoc. Prof. \\ University of Medicine, Tirana, Albania \\ Enida Balla, M.Sc. \\ University Hospital Center "Mother Teresa,, Tirana, Albania
}

Doi: 10.19044/esj.2018.v14n21p278 URL:http://dx.doi.org/10.19044/esj.2018.v14n21p278

\begin{abstract}
The costs associated with current and emerging therapies, as well as supportive care, are significant and pose a tremendous financial burden to both patients and healthcare system. The objective of this study was to calculate the cost savings as a result of bortezomib vial sharing in the University Hospital Center "Mother Teresa" Tirana. This study was a retrospective analysis of the use of bortezomib in patients with multiple myeloma, using vial sharing technique to minimize wastage. The study has been conducted during the period January 1, 2015 to June 30, 2015 before vial sharing and January 1, 2016 to June 30, 2016 after vial sharing, thereby enabling us to share vial contents between patients. We compared the cost in euro for the treatment with bortezomib in order to determine the cost savings of vial sharing and cost-efficacy of individualised preparation. As a result, the cost savings for one cycle/patient using vial sharing was calculated 226.81 euro, a reduction of $25.96 \%$ compared to the period when we did not use vial sharing. During January 1, 2015 to June 30, 2015 the average treatment cost was calculated 873.36 euro/cycle/patient, compared with January 1, 2016 to June 30, 2016 when it was calculated 646.55 euro/cycle/patient. Due to cost savings of each treatment cycle we administered 62 individualised preparations of bortezomib more during January 1, 2016 to June 30, 2016 for the same budget allocated. The same approach should be adopted for other suitable drugs prepared in the University Hospital Center "Mother Teresa" Tirana.
\end{abstract}

Keywords: Bortezomib, cost savings, vial sharing, Albania 


\section{Introduction}

Multiple myeloma is a blood cancer related to lymphoma and leukemia. Despite many advances in therapy, there is currently no curative treatment available but there are treatments that slow down its spread. Pharmacological treatment includes chemotherapy, corticosteroids and targeted therapies such as immunomodulators, monoclonal antibodies, proteasome inhibitors, HDAC inhibitors and bisphosphonates, which has changed the standards of care for affected patients. Although the current achievements in therapy there is a lot to be done for patients diagnosed with multiple myeloma to extend their survival and to improve their quality of life (Durie, 2010, Laubach, Richardson \& Anderson, 2010, Ludwig, Beksac, Blade, et al., 2010, Richardson, 2010). The advance in cancer knowledge and progresses on development of new molecules and treatment schedules offer our patients greater expectations in terms of response, prolonged survival, or improved quality of life. On the other hand, these new tools are very expensive and the availability of resources is limited, so they should be used in an efficient and equitable manner (Baselga, \& Carrato, 2008). New treatment protocols and new classes of drugs are more expensive than the older ones.

Hence, the costs associated with current and emerging therapies, as well as supportive care, are significant and pose a tremendous financial burden to both patients and healthcare system (Cook, 2008). This can be an obstacle for the treatment of patients with multiple myeloma and sometimes the decision related to the treatment of choice is made taking in consideration primarily the therapy costs and not the efficacy and clinical outcomes of the patients, especially in poor countries and developing countries, where the healthcare system financing is low and the budget allocated for drugs is not sufficient. Cancer is becoming a major priority for health policies in Albania for two major reasons: the increase of mortality and morbidity rates for a number of cancers and the delays in diagnosis. The Hematology Department of the University Hospital Centre "Mother Teresa" Tirana is the only public health structure that offers multidisciplinary treatment for multiple myeloma patients in Albania.

The dose of many anti-cancer medications is calculated based on patient weight or body surface area (BSA) (Cheesman, Shields, Shah, et al., 2016). Although doctors and hospitals sometimes use leftover drug to treat a subsequent patient, thus reducing the amount of leftover drug for which they bill, this practice is very limited. Safety standards from the US Pharmacopeial Convention permit sharing only if leftover drug is used within six hours, and only in specialized pharmacies (Smith, 2015, United States Pharmacopeia, ed. USP <797> 2008, Fasola, Aprile, Marini, et al., 2014). Cost savings approaches are directly related to the drug preparation process. We know that most anticancer drugs are individually dosed according to a patient's body 
surface and that pharmaceutical products do not exactly fit the dose required in a specific patient, generating residual amounts of unused drugs. The waste of drugs caused from the vials size also affects the financial costs of the treatment. Single-size vials of chemotherapy drugs may be an under noticed source of waste and increase in treatment costs. An effective method to reduce the drugs waste is the possibility to choose between vials size depending on the patient's need. It is also possible to reduce the waste of drugs using individualized preparation. The rational application of personalized dose principle may reduce the anticancer drug expenditures (Mertens, \& de Jongh, 2009). Some other possible saving approaches have been proposed, such as dose rounding to the nearest vial size (Dooley, Singh, \& Michael, 2004), dose standardization of anticancer drugs (Pouliquen, Escalup, Jourdan, et al., 2011) and selecting the most convenient vial size. In this framework, a project of drug waste reduction was designed and launched at the end of 2015 in the Hematology Department of the University Hospital Center "Mother Teresa" Tirana. The project aimed to estimate the economic benefit and the relative influence of the cost savings as a result of vial sharing while respecting drug stability.

Bortezomib (Velcade, Janssen-Cilag, Beerse, Antwerp, Belgium) is a drug frequently used in multiple myeloma treatment that is available in Albania, U.S.A, Brazil and in many other countries only as a 3.5-mg vial. This presentation dose is higher than the average dose commonly prescribed and due to the lack of preservatives in the vial, it is mandatory that the drug be administered within a couple of hours from the preparation (Mertens, \& de Jongh, 2009). Bortezomib is available in the U.S.A in only a $3.5 \mathrm{mg}$ vial, much larger than the average required dose, which has been calculated to be approximately $2.5-2.6 \mathrm{mg}$ based on the drug's dose of $1.3 \mathrm{mg} / \mathrm{m}^{2}$ and the average weight of a cancer patient. It is estimated that $27 \%$ to $30 \%$ of bortezomib sales in the U.S.A are related to leftover drug equating to $\$ 309 \mathrm{~m}$. The drug is sold in 3.5mg and $1 \mathrm{mg}$ vials in the UK (Clark, Castro, Fortes, et al., 2011).

The objective of this study was to calculate the cost savings as a result of bortezomib vial sharing in the University Hospital Center "Mother Teresa" Tirana, to obtain data for Albania in order to be able in the future to reduce furthermore the treatment costs without affecting the clinical outcome of the patients and the safety of drugs and to make comparative studies with other countries.

\section{Methods}

Study design: This study was a retrospective analysis of the use of bortezomib individualised treatment in patients with multiple myeloma, using vial sharing technique to minimize wastage, which allows residual amounts 
of unused drugs to be reused by patients whose treatments are elaborated in the same working day, with focus on practicality and cost savings. The study was conducted in the period January 1, 2015 to June 30, 2015 before vial sharing and January 1, 2016 to June 30, 2016 after vial sharing, thereby enabling us to share vial contents between patients and minimize drug wastage. Preparation of bortezomib individualized therapy occurred in the biosafety cabinet of the Hematology pharmacy in the University Hospital Center "Mother Teresa" Tirana. All doses were prepared for administration by subcutaneous bolus injection as a dilution of bortezomib in sodium chloride $0.9 \%$. In order to protect the patient's anonymity, the patient's name or any particular characteristic during this study have not been revealed. Folders and medical prescriptions of bortezomib were used for this study. The Hematology pharmacy calculated the amount of bortezomib needed to prepare the prescribed dose, if vials are shared by patients whose treatments are elaborated in the same working day. We compared the cost savings in euro for the treatment with the same drug for each treatment cycle to calculate the total number of cycles and total vials of bortezomib used in the period January 1, 2015 to June 30, 2015 in comparison with January 1, 2016 to June 30, 2016 in order to determine the cost savings and cost-efficacy of the individualised preparation and vial sharing. The average cost for each bortezomib dose was retrospectively calculated as the average procured price in 2015 and 2016, years in which the study was conducted. The mean and average calculations were performed based on usual mathematical formulas and were represented in euro. The amount of drug wasted was also expressed in percentage related to the total content of the $3.5-\mathrm{mg}$ vial. The results of costs were expressed in euro with the cost of the $3.5 \mathrm{mg}$ bortezomib vial calculated $873.36 €$ (exchange rate ALL137.4 to $€ 1$ as of 2016).

\section{Results}

We evaluated the consequent cost savings of bortezomib vial sharing. During the study period, vial consumption data were obtained, absolute savings were expressed as number of vials and the cost savings were determined using bortezomib calculations. All costs are expressed in euro. The cost savings as a result of bortezomib vial sharing for one patient for each treatment cycle was calculated 226.81 euro, a reduction of $25.96 \%$ compared to the period when we didn't use vial sharing to minimize drug wastage as result of the vial size. During the period January 1, 2015 to June 30, 2015 the average treatment cost was calculated 873.36 euro/cycle/patient, compared with January 1, 2016 to June 30, 2016 when it was calculated 646.55 euro/cycle/patient. The average required dose of bortezomib, has been calculated to be $2.59 \mathrm{mg}$ based on the drug's dose of $1.3 \mathrm{mg} / \mathrm{m}^{2}$ and the average weight of the treated patients. The drug wastage during the period 
January 1, 2015 to June 30, 2015 was calculated $162.89 \mathrm{mg}$ equivalent to 46.54 vials of $3.5 \mathrm{mg}$ bortezomib with a total cost of waste estimated to be 40646.17 euro in comparison with the period January 1, 2016 to June 30, 2016 in which the drug wastage was calculated $10.2 \mathrm{mg}$, equivalent to 2.91 vials of $3.5 \mathrm{mg}$ bortezomib with a total cost of waste estimated to be 2541.47 euro. The difference in euro for the drug wastage comparing January 1, 2015 to June 30, 2015 and January 1, 2016 to June 30, 2016 was estimated to be 38104.07 euro equivalent to 46.63 vials of $3.5 \mathrm{mg}$ bortezomib. As a result of cost savings due to vial sharing we administered 62 individualized preparations of bortezomib more in January 1, 2016 to June 30, 2016 for the same budget allocated. Following you can find the calculations for bortezomib in Table 1.

Table 1. Calculations of costs and waste of bortezomib before and after vial sharing

\begin{tabular}{|c|c|c|c|c|c|c|c|}
\hline $\begin{array}{c}\text { Period of } \\
\text { time }\end{array}$ & $\begin{array}{c}\text { Number of } \\
\text { patients } \\
\text { treated with } \\
\text { bortezomib }\end{array}$ & $\begin{array}{c}\text { Number of } \\
\text { bortezomib } \\
\text { vials used }\end{array}$ & $\begin{array}{c}\text { Cost of } \\
\text { treatment for 1 } \\
\text { patient/cycle }\end{array}$ & $\begin{array}{c}\text { Average dose } \\
\text { of bortezomib } \\
\text { for 1 } \\
\text { patient/cycle }\end{array}$ & $\begin{array}{c}\text { Waste in } \\
\text { mg from } \\
\text { current } \\
\text { vial size }\end{array}$ & $\begin{array}{c}\text { Waste in } \\
\text { vials of 3.5 } \\
\text { mg } \\
\text { bortezomib }\end{array}$ & $\begin{array}{c}\text { Waste in } \\
\text { euro }\end{array}$ \\
\hline $\begin{array}{c}01.01 .2015- \\
30.06 .2015\end{array}$ & 179 & 179 & $873.36 €$ & $2.59 \mathrm{mg}$ & $162.89 \mathrm{mg}$ & 46.54 & $40,646.17 €$ \\
\hline $\begin{array}{c}01.01 .2016- \\
30.06 .2016\end{array}$ & 258 & 191 & $646.55 €$ & $2.59 \mathrm{mg}$ & $10.2 \mathrm{mg}$ & 2.91 & $2,541.47 €$ \\
\hline
\end{tabular}

\section{Discussion}

The rational application of the dose individualization principle based on body surface area may result in a substantial reduction in expenditure on anticancer drugs (Nava-Ocampo, Alarcon-Almanza, Moyao-Garcia, et al., 2004) including bortezomib. Drug waste may be defined as the consequence of an inappropriate disposal of unused or partially used ampoules, vials, or syringes of drugs (Gillerman, \& Browning, 2000). It has been previously demonstrated that inefficiency of drug use and waste production may lead to a distinct economic loss, though experiences are limited and most studies are dated or focus on other therapeutic areas (Gillerman, \& Browning, 2000, Fasola, Aita, Marini, et al., 2008). Decreasing waste is an attractive costcutting strategy because it neither limits specific drug use nor affects quality of care (Mertens, \& de Jongh, 2009).

The leftover amount of the used drug depends on the number of patients attended, anthropometric characteristics, the time between patients who receive the same drug and the marketed vials. One of the main reasons for drug waste was essentially the limited extent of chemotherapy medication shelf-life and the narrow availability of a range of vial sizes flexibly matching with possible drug dosages (Fasola, Aita, Marini, et al., 2008). Therefore, a change in the management process would minimize the overall health expenditure without adversely impacting patient's health outcomes. This is 
one of the biggest future challenges of health systems in the current economic environment (Sullivan, Peppercorn, Sikora, et al., 2011). In the last years, there has been much discussion on the rising prices of oncologic treatments and how much is too much (Meropol, \& Schulman, 2007). We believe that this discussion is even more important in developing countries, such as Albania, which are concerned by a permanently insufficient healthcare budget. This analysis intended to give information on how we can reduce costs and minimize drug wastage of bortezomib simply with vial sharing technique.

Finally, we think that after the installation of the centralized unit, new working habits have been developed. The benefits of this change in paradigms into cooperation could be defined as a combination of reaching the goal of giving the right drug, with the right dosage, to the right patient, at the right time, at a more cost-efficient level.

\section{Conclusion}

Vial sharing of bortezomib between patients combining multiple infusions on the same day has improved patient experience by increasing access to therapy and reducing waiting times for treatment. Drug costs were reduced by $25.96 \%$ resulting in significant savings and more patients treated with the same amount of vials of bortezomib used. Our experience confirms the economic benefit of waste reduction and cost savings effect due to vial sharing, especially when used in large centers. The same approach should be adopted for other suitable drugs prepared in the bio-safety cabinet in the University Hospital Center "Mother Teresa" Tirana. A centralized unit of anticancer drug preparation increases the drug traceability from preparation to patient. We think that we should initiate a centralization project in the University Hospital "Mother Teresa" Tirana in order to reach the goal of "the right drug, with the right dosage, to the right patient, at the right time, at the right cost".

\section{References:}

1. Durie BG. (2010). Role of new treatment approaches in defining treatment goals in multiple myeloma-the ultimate goal is extended survival. Cancer Treat Rev, 36 (Suppl. 2):S18 -23.

2. Laubach JP, Richardson PG, Anderson KC. (2010). The evolution and impact of therapy in multiple myeloma. Med Oncol, 27 (Suppl. 1):S16.

3. Ludwig H, Beksac M, Blade J, et al. (2010). Current multiple myeloma treatment strategies with novel agents: a European perspective. Oncologist, 15:6-25. 
4. Richardson PG. (2010). Frontline multiple myeloma management: a clinical and cost update for managed care. In: Education NACfCM, ed., Continued Medical Education. Boston: Jerome Lipper Multiple Myeloma Center, Dana-Farber Cancer Institute, Harvard Medical School.

5. Baselga, J., Carrato, A. (2008). Investigación sobre el cáncer en beneficio del paciente. Rev Esp Econ Salud; 6 (3):135.

6. Cook R. (2008). Economic and clinical impact of multiple myeloma to managed care. J Manag Care Pharm, 14:19-25.

7. Cheesman S., Shields A., Shah R., et al. (2016). Vial Sharing of Bortezomib Is Logistically Feasible and Significantly Reduces Drug Wastage and the Cost of Myeloma Treatment. Blood, 128:5956.

8. Smith RS. (2015). A 2-year retrospective review of vial sharing options for the compounding of cytotoxics. Eur J Hosp Pharm, 22:1614. doi: http://dx.doi.org./doi:10.1136/ejhpharm-2014-000547

9. United States Pharmacopeia, ed. USP <797> (2008). Guidebook to pharmaceutical compounding-sterile preparations. United States Pharmacopeial Convention.

10. Fasola G, Aprile G, Marini L, Follador A, Mansutti M, Miscoria M. (2014). Drug waste minimization as an effective strategy of costcontainment in oncology. BMC Health Serv Res, 14:57. doi:10.1186/1472-6963-14-57. 24507545.

11. Mertens, S. and de Jongh, F.E. (2009). Lower costs for anticancer drugs by safety margin around calculated dose and by fine-tuning on ampoule strength. Ned Tijdschr Geneeskd. 153:B162.

12. Dooley, MJ., Singh, S., Michael, M. (2004). Implications of dose rounding of chemotherapy to the nearest vial size. Support Care Cancer; 12 (9):653-6.

13. Pouliquen, AL., Escalup, L., Jourdan, N., Cottu, P., Faure, P., Madelaine-Chambrin, I. (2011). Dose standardisation of anticancer drugs. Int J Clin Pharm; 33 (2):221-8.

14. Clark L, Castro AP, Fortes AF, et al. (2011). Ideal vial size for bortezomib: real-world data on waste and cost reduction in treatment of multiple myeloma in Brazil. Value Health., 14(5 Suppl 1): S82-4. doi: 10.1016/j.jval.2011.05.013.

15. Nava-Ocampo AA, Alarcon-Almanza JM, Moyao-Garcia D, et al. (2004). Undocumented drug utilization and drug waste increase costs of pediatric anesthesia care. Fundam Clin Pharmacol, 18:107-12.

16. Gillerman RG, Browning RA. (2000). Drug use inefficiency: a hidden source of wasted health care dollars. Anesth Analg, 91:921-4. 
17. Fasola, G., Aita, M., Marini, L. et al. (2008). Drug waste minimisation and cost-containment in medical oncology: two-year results of a feasibility study. BMC Health Serv Res., 8: 70.

18. Sullivan, R., Peppercorn, J., Sikora, K., Zalcberg, J., Meropol, NJ., Amir, E., et al. (2011). Delivering affordable cancer care in highincome countries. Lancet Oncol;12 (10):933-80.

19. Meropol NJ, Schulman KA. (2007). Cost of cancer care: issues and implications. J Clin Oncol, 25:180-6. 